\title{
Forever Young? The Desire for Attractiveness and Youthfulness
}

\section{at Advanced Age}

\author{
Brigitte Jenull, Nadja Frate, Carlotta Mayer \\ Alpen-Adria-Universität Klagenfurt, Carinthia, Austria
}

\begin{abstract}
Media and advancement in technology prepared ideal images enhancing many people's desire for being forever young and looking youthful. The present study uses a mixed methods design to investigate body satisfaction and anti-aging behavior in women and men over 50 years of age. The findings indicate that most of the participants ( $N$ $=126,78 \%$ ) feel younger than they are but also less attractive than the younger sample which leads to a lower level of satisfaction. Results also show differences in participants' health and beauty behavior concerning their perceived attractiveness, their age, and BMI. Participants' most disliked body part is their belly. An age appropriate clothing style also seemed to be important to the sampling. In a society with performance-related demands, even with strange ideal images of aging, the development and maintenance of a positive age identity becomes a great challenge.
\end{abstract}

Keywords: advanced age, aging, anti-aging, body satisfaction, age identity, clothing styles

\section{Introduction}

Current demographic development leads to an old society. Aging is an integral part of development and can be described as a complex process marked by biological, psychological, social, and ecological influences (Kruse \& Wahl, 2010; Thomae, 1993). Each aspect changes while aging and maintaining usual functionality gets more and more difficult. Seniority begins with the termination of employment and may last up to 40 years. For a better understanding the complexity of seniority, aging research distinguishes between the third and fourth age (Baltes, 1997; Laslett, 1995). The third age, known as the young old (Martin \& Kliegel, 2008), contains 65-80 year old people whose physical and mental functioning contributes to a positive view of age and aging (Baltes, 2007). Age-specific functional losses are increasingly evident in the fourth age, to which the over 80-year-olds are attributed. Those are known as the elderly olds. Multimorbidity, mobility problems as well as pain increase rapidly (Walter, Hager, \& Lux, 2008; Weber, Ferring, \& Glück, 2008) and create a more negative view of aging. In addition to the typical experiences of loss in physicality, attractiveness, performance, and fulfilment of roles, old age also stands for the final anchoring in life, if a positive review of life succeeds in the sense of generativity (Kruse \& Wahl, 2010).

Brigitte Jenull, Ph.D., psychologist, psychotherapist, Department of Health Psychology, Alpen-Adria-Universität Klagenfurt, Carinthia, Austria.

Nadja Frate, Ph.D. student, Department of Health Psychology, Alpen-Adria-Universität Klagenfurt, Carinthia, Austria.

Carlotta Mayer, research assistant, Department of Health Psychology, Alpen-Adria-Universität Klagenfurt, Carinthia, Austria. 
The diversity and complexity of aging processes lead to individual comparisons, which makes the associated mental state ambivalent. This modern, less deficient view of aging offers the young old in particular a new space for personal development. We can find this correspondence of view in the golden or best agers, presented as attractive, dynamic, and independent people who plunge into a new phase of life full of vigor. Despite this positive presentation it is important to note that elderly people are either shown changed or do not appear at all (Höppner, 2011). The propagated cult of youth shows the aged woman almost wrinkle-free, fit and youthfully beautiful, although naturally aging women are rare. Instead, actresses, musicians, or other public women who have already passed the age of 50 are praised as sex symbols embodying the ideal woman of advanced age: a smooth forehead, a glowing face, a perfect and firm body and, at least outwardly, not aged in the last 20 years. This presentation of women of advanced age holds an ideal that many women cannot achieve. Today's society may see aging as a disease that everyone should heal by maintaining a youthful appearance and avoiding aging (Cardona, 2008; Slevin, 2010).

A gender-specific view shows that women are considered faster as old. The different social evaluation of the age and aging of women and men becomes clear by the fact that women are called old as soon as they have exceeded adolescent age (Maierhofer, 2007). Another view is that women with a loss of reproductive capacity, so mostly from their mid-40s, are considered old (Gildemeister \& Robert, 2008). For men, age would start in their mid-60s and may be associated with positive feelings and characteristics in men. Grey hair in men is seen as more aesthetic as in women of the same age which is a phenomenon called the double standard of aging (Sontag, 1979). Women are significantly more affected by age discrimination. The convention, which states that women must not be asked about their biological age, is also an indication of the sensitivity of this topic (Derra, 2012).

The fact that many women want to balance their appearance with their inner self can be seen in the comparison of perceived and actual age. A positive age identity exists when the surveyed person feels younger than they actually are; if the perceived age exceeds the calendar age, this indicates a negative age identity (Westerhof \& Barrett, 2005). According to Featherstone and Hepworth (1991), many people feel younger than they actually are and perceive their appearance as a mask. The discrepancy between the external appearance and the internal subjective feeling is reflected in the age mask, which conceals the individual self or identity of the person. A study showed that people of advanced age rarely use the word old to describe themselves. Instead, they use the word elder (Jones, 2006). This is supported by the subjective age bias, describing the feeling of being young despite aging (Weiss \& Lang, 2012). This bias is not only a good indicator of mental well-being and high self-esteem, but increases with advancing age (Knoll, Rieckmann, Scholz, \& Schwarzer, 2004; Weiss \& Lang, 2012; Westerhof \& Barrett, 2005). Such a gap between perceived and chronological age is not suspected in childhood or early adulthood (Rubin \& Berntsen, 2006).

The perception of one's own age and aging is mostly experienced physically and the dissatisfaction of women with one's own body seems omnipresent. Dissatisfaction with one's own body has increased worldwide in recent decades because of fashion trends disseminated by the media. Body weight as well as shape and size of the own body are the main characteristics of appearance leading to dissatisfaction (Burke, Schaefer, \& Thompson, 2012). By internalizing the ideal of beauty, women are under pressure to be as slim, flawless and young as media claim-forgetting digital retouching and the fact that only five percent of women have the biological prerequisites to meet the common ideals (Gläßel, 2011). One of the most important theories to explain body 
dissatisfaction is the objectification theory of Frederickson and Roberts (1997). It is because the female body, even from the days of the little girl, has been evaluated from the outside. This evaluation is carried out in the interpersonal and social (girls are seen more than boys are) as well as in the media area (women are presented as attractive and sexually interesting). This leads to an object-like depiction and presentation of one's own body, i.e., the view of women is directed at their body as if it were an object that they judge. Parents and especially mothers are important for the development of an infantile body image (Levine \& Chapman, 2011). A derogatory feedback from mothers, maternal rejection of the daughter's figure, the mother's eating habits perceived by the daughter, and the mother's attitude towards the body image are seen as negative influences on the body image (Cooley, Torey, Wang, \& Valdez, 2008).

Pook, Brähler, and Tuschen-Caffier (2009) investigated body satisfaction on a sample of 1,060 women between 14 and 93 years. The results show that women over 65 are less dissatisfied with their bodies. Similar results were found in a study from Öberg and Tornstam (1999): The body satisfaction of women improved in higher decades of life and was even similar to those of men from the age of $75+$. Another study investigated the influence of age on a positive body image, as well as the influence of age on the relationship between positive body image and body satisfaction (Tiggemann \& McCourt, 2013). Results show a positive linear link between age and body satisfaction and a positive correlation between body image and body dissatisfaction in all ages. Nevertheless, the link between body image and dissatisfaction with the body was less in older women. Researchers increasingly agree that the body image of older women changes throughout their lives and is an important source of self-esteem (Baker \& Gringart, 2009).

The pressure of being beautiful and looking youthfully has been booming the beauty industry since the 1990s (Petersen \& Seear, 2009). To lure women into the anti-aging trap, it is suggested that signs of aging such as wrinkles, a shapeless bosom or brittle skin are abnormal (Smirnova, 2012). Anti-aging products, which promise to turn women into an eternal fountain of youth or at least to make them look like such, are being used more and more. Although the effect of these products is questionable, they are still bought and used (Muise \& Desmarais, 2010). According to the authors, this could be explained by users' feeling to control their aging processes. Gildemeister and Robert (2008) state that being beautiful is equal to being youthful; having the appearance of an old woman is considered by many to be negative. The body is therefore not seen as something unchangeable that has been given to you and which you must accept. Rather, our postmodern society strives to compensate for and modify physical decay. Age and aging is more and more a project with individual responsibility; the body becomes a task of self-optimization (Posch, 2009). To keep the calendrical age low, the Doing Beautification Age changes external signs of aging and manipulates the body (Höppner, 2011; Klein, 2010). This beauty treatment also includes changing the hair color, applying make-up and activities that can modify the weight or appearance of the body, such as fitness or a diet. Results show that patients who have undergone plastic surgery are getting older, with 80.4\% more women than men (Deutsche Gesellschaft für Ästhetisch-Plastische Chirurgie (DGÄPC), German Society for Aesthetic Plastic Surgery, 2017). On average, women undergoing plastic surgery are almost 42 years old. Operations with great popularity are liposuction, eyelid lift, non-invasive treatments, and botulinum treatments (DGÄPC, 2017). A study shows that most of the women of a mixed sample between 60 and 89 years speak up for plastic surgery and even already had one or were planning to undergo plastic surgery. 
For being a part of a youth society, acting in beauty or the creation of beauty becomes a central act of identity (Posch, 2009). If people define themselves over their appearance, clothing is also very important. Through the style of clothing, people express their own individuality and can show themselves more or less youthfully in the sense of doing age. Just as the human body changes over time, so does the style of clothing. In the third age, women show more interest in looking good by adapting their clothes to their changed body and thus compensating or hiding blemishes as well as possible (Twigg, 2007). In the fourth age, fashion fades into the background; instead, more value is placed on functionality. Elder women tend to wear certain clothes. This is longer and less formless, and has more subtle, darker and softer colours, such as grey, beige, lilac, or navy blue (Lurie, 1992). Although there are no special clothes for women of advanced age, there seems to be rules that are taken into account when choosing clothes. Inappropriate youthful or provocative clothing behaviour is considered inappropriate. A study investigated opinions to a photography of a 73 old woman with probably black coloured hair, jeans, a blouse with a lot of cleavage, high heels, and gold jewelry (Rexbye \& Povlsen, 2007). The majority of responses of participants between 22 and 87 years old were negative. The woman shown was described with adjectives like cheap and untrustworthy. Moreover, she was accused of not being able to age gracefully. The authors conclude that this type of clothing exudes sexual activity that is considered unacceptable by study participants and society at a certain age. Rather, it is suggested that the radiation of sexuality is reserved for young people or young adults. The body and clothing style of older women should be invisible (Höppner, 2011). Therefore, there seems to be rules for wearing certain clothes, the violation of which is sanctioned by society.

In a youth-oriented society, therefore, physically idealizing messages motivate older women to maintain their youthfulness behind the mask of aging. This increases the pressure to constantly renew oneself externally through anti-aging and doing age strategies. The present study explores in an explorative way in which the pressure to look youthful affects age identity. Aspects of feeling younger and the body satisfaction of women of advanced age are taken into account. Furthermore, individual patterns of action, i.e., anti-aging and doing age strategies, are asked and an opinion on rules of behaviour in old age is collected.

\section{Method}

For the mixed method study, women and men were sought who had already reached or exceeded the age of 50 years. The lower age limit was set around the age of 50 years, as women are considered old when they enter the menopause (Gildemeister \& Robert, 2008). The participants were attracted to the study by the pyramid scheme. Thus, the questionnaires were first sent to friends and family, after which they were passed on to friends and acquaintances.

\section{Instruments}

In order to determine the body satisfaction the questionnaire for the evaluation of the own body (Fragebogen zur Beurteilung des eigenen Körpers, FBeK) of Strauß and Richter-Appelt (1996) was used. The FBeK is a standardized questionnaire and consists of 52 items in the four subscales attractiveness/self-confidence (scale 1, including 15 items), accentuation of the physical appearance (scale 2, including 12 items), uncertainty/concern (scale 3, including 13 items), and physical-sexual discomfort (scale 4, including 6 items). Scale 3 was not investigated because of the missing thematic context; therefore the number of items from the FBeK in the present study is 39 . 
In addition, participants were asked to indicate age, height, and weight. This information was used to calculate the BMI for each study participant. The participants were then divided into the categories underweight (BMI < 18.5), normal weight (BMI 18.5-24.9), overweight (BMI 25-29.9), obesity grade I (BMI 30-34.9), obesity grade II (BMI 35-39.9), and obesity grade III (BMI > 39.9) according to WHO guidelines (WHO, 2000).

This was followed by questions on graduation, marital status, household size, professional group membership, and monthly household income in order to calculate the net equivalised income according to the OECD scale (Volkert, Klee, Kleimann, Scheurle, \& Schneider, 2003) and to assign the participants to a low, medium, or high socio-economic status (SES) (Lampert, Müters, Stolzenberg, \& Kroll, 2014).

Furthermore, the study participants were asked how old they feel (perceived age). Further questions were aimed at obtaining information on the standard beauty program and health behavior. Then an image of the female or male body (see Figure 1) was presented. Participants should mark the areas that they would surgically change if they had the opportunity to do so. The last question was about clothing rules for advanced age (Do you think that there are unwritten rules for wearing certain clothes for women/men of advanced age?).
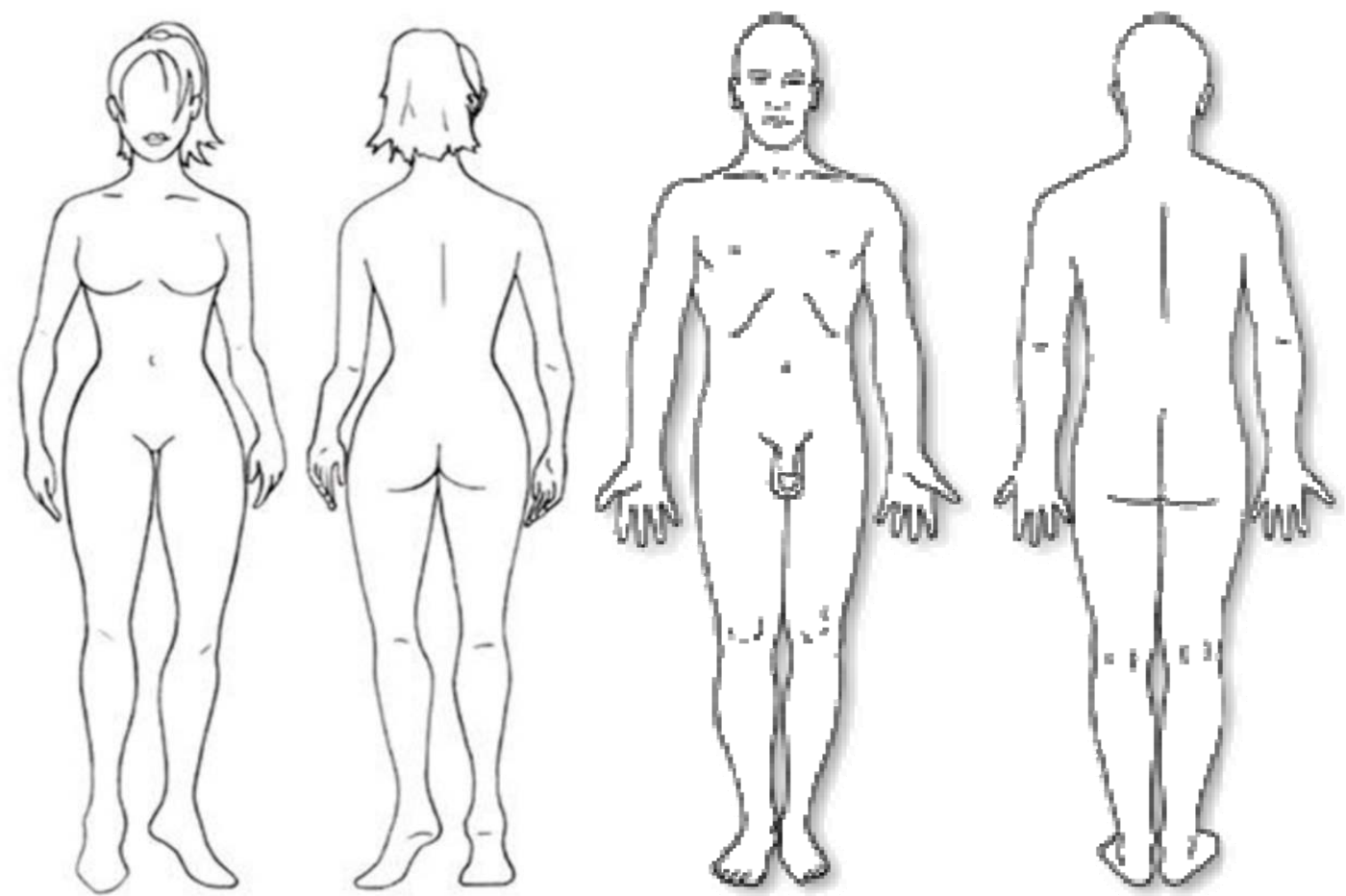

Figure 1. Schematic representation of the female and male body (http://2.bp.blogspot.com/.../Women+Hourglass.JPG).

The SPSS program was used to calculate and evaluate the questionnaires. The results were compared with the FBeK norm sample. The open questions regarding the clothing rules for advanced age and the standard beauty program were evaluated with the qualitative content analysis according to Mayring (2008).

\section{Results}

\section{Age and Perceived Age}

126 people took part in this study. Of these, 62 were male (49\%) and 64 female (51\%). The average age of the participants was $58.52(S D=7.96)$ years, with the youngest participant aged 49 and the oldest participant 84 . 
The participants were also asked about their perceived age. Only 15 out of 124 participants (12\%) felt as old as they actually are. 12 people (10\%) felt older and 97 felt younger (78\%).

\section{Socioeconomic Status}

The monthly "equivalent household disposable income” of the participants was, on average, 2,004 Euro (SD $=1149.47$ ). In the Austrian comparison, this income is in the lower quartile range (Statistik Austria, 2017).

Table 1

Categories of the SES

\begin{tabular}{lll}
\hline SES categories $(n=122)$ & Frequency & Percent \\
\hline Low $(3-8.4)$ & 17 & $14 \%$ \\
Medium (8.5-15.4) & 55 & $45 \%$ \\
High $(15.5-21)$ & 50 & $41 \%$ \\
\hline
\end{tabular}

\section{Weight}

The sample's BMI distribution is shown in Table 2.

Table 2

Distribution of the Sample's BMI

\begin{tabular}{lll}
\hline & Frequency & Percent \\
\hline Underweight & 1 & $1 \%$ \\
Normal weight & 64 & $51 \%$ \\
Overweight & 50 & $40 \%$ \\
Obesity & 10 & $8 \%$ \\
\hline
\end{tabular}

Critically, the changes in body structure associated with age, such as a decrease in muscle mass, an increase in fat mass (Hughes, Frontera, Roubenoff, Evans, \& Singh, 2002), or a decrease in body size (Sorkin, Muller, \& Andres, 1999), have not been taken into account in this study. Although the usefulness of using BMI in older people is often questioned because of the aspects mentioned (Zamboni et al., 2005), the WHO recommendation to use the same cut-off values as for younger people (WHO, 2004) is maintained in the absence of age-adapted standard and target values (Lechleitner, 2013).

\section{Body Satisfaction}

Data on the assessment of the participants' own bodies were compared with the norm sample, which was collected from female students in 1993. Comparisons between this norm sample and the sample of the present study can be found in Table 3 .

Table 3

Comparisons Between the Present Sample and the Norm Sample

\begin{tabular}{llll}
\hline Scale & Norm sample & Present sample & T-Test \\
\hline 1. Attractiveness/self-confidence & $M=11.50$ & $M=9.73$ & $p=0.001$ \\
& $S D=3.50$ & $S D=3.88$ & \\
2. Accentuation of the physical appearance & $M=7.50$ & $M=6.40$ & $p<0.001$ \\
3. Physical-sexual discomfort & $S D=2.60$ & $S D=2.25$ & \\
& $M=1.80$ & $M=1.81$ & $p=0.774$ \\
\hline
\end{tabular}


For the first scale, results show a significant difference $(p=0.001)$. In this sample, lower levels of attractiveness and self-confidence were reported. The second scale also showed significantly lower mean values compared to the norm sample concerning the accentuation of the appearance $(p<0.001)$. No significant differences were observed within the scale of "physical-sexual discomfort" $(p>0.05)$.

This shows that the participants over 50 have a lower value in terms of attractiveness and self-confidence. They also have less pleasure with their own appearance and are less occupied with their own body.

In order to identify possible differences between different age groups in the individual scales, two age categories were formed and t-tests were calculated for independent samples. The first group includes participants under 60 years ( $n=78,62 \%)$, the second group participants over 60 years $(n=48,38 \%)$. Significant differences ( $p=0.006$ ) were only found in scale 2 (accentuation of appearance).

Using the chi²-test, differences were found in the items "Many people make too much effort around their bodies" ( $\left.X^{2}=5.127, d f=1, p=0.024\right)$ and the item "I often and like to look at myself" $\left(X^{2}=6.044, d f=1, p=\right.$ 0.014).

A t-test for independent samples, which examined gender differences, showed significant differences in scale $2(p=0.037)$ and scale $3(p=0.042)$. More tests for gender differences within the items showed the following results:

Women:

- It makes me feel insecure when something about my appearance is not what it should be $\left(X^{2}=12.702, d f=1\right.$, $p<0.001)$.

- If I don't look good, I feel uncomfortable $\left(X^{2}=16.935, d f=1, p<0.001\right)$.

- Taking a shower or a bath is more than a body cleansing for me $\left(X^{2}=6.306, d f=1, p=0.012\right)$.

- When someone says something negative about my appearance, it hits me very hard $\left(X^{2}=19.344, d f=1, p<\right.$ $0.001)$.

Men:

- The idea that others see me naked makes me uncomfortable $\left(X^{2}=8.980, d f=1, p=0.003\right)$.

- I find it hard to imagine that others find me attractive $\left(X^{2}=5.702, d f=1, p=0.017\right)$.

- Sometimes I get angry at my body $\left(X^{2}=4.895, d f=1, p=0.027\right)$.

\section{Beauty Behavior}

Furthermore, the participants were asked about their standard beauty program (Table 4).

Table 4

Standard Beauty Program

\begin{tabular}{lll}
\hline & $\begin{array}{l}\text { Women } \\
\mathrm{n}=64\end{array}$ & $\begin{array}{l}\text { Men } \\
\mathrm{n}=62\end{array}$ \\
\hline Hairdressing & $51(80 \%)$ & $50(81 \%)$ \\
Hair dyeing & $47(73 \%)$ & $6(10 \%)$ \\
Tanning & $7(11 \%)$ & $1(2 \%)$ \\
Anti-aging cremes & $35(55 \%)$ & $7(11 \%)$ \\
Manicure & $33(52 \%)$ & $11(18 \%)$ \\
Pedicure & $32(50 \%)$ & $15(24 \%)$ \\
Make-up & $31(48 \%)$ & - \\
\hline
\end{tabular}


(table 4 continued)

\begin{tabular}{lll}
\hline & $\begin{array}{l}\text { Women } \\
\mathrm{n}=64\end{array}$ & $\begin{array}{l}\text { Men } \\
\mathrm{n}=62\end{array}$ \\
\hline Hair removal armpits & $44(69 \%)$ & $10(16 \%)$ \\
Hair removal legs & $42(66 \%)$ & $1(2 \%)$ \\
Hair removal private parts & $29(45 \%)$ & $7(11 \%)$ \\
Hair removal back & $2(3 \%)$ & $3(5 \%)$ \\
Hair removal chest & $5(8 \%)$ & $3(5 \%)$ \\
Hair removal face & $22(34 \%)$ & $32(52 \%)$ \\
Cosmetic dental treatment & $11(17 \%)$ & $11(18 \%)$ \\
\hline
\end{tabular}

Notes. Multiple answers were possible.

The standard beauty program for women includes hairdressing, hair dyeing, and hair removal. In men, it is also hairdressing and facial hair removal.

Within the framework of the standard beauty program, an average of six nominations for women and three nominations for men were approved. The sum of the nomination frequencies for the standard beauty program, i.e., a distinct standard beauty program, correlates highly significant with the scale 2 of FBeK $(r=0.352, p<0.001)$ and highly significant negative with age $(r=-0.267, p=0.003)$ and BMI $(r=-0.250, p=0.005)$.

\section{Health Behavior}

Table 5 shows the frequencies of the participants' standard health program.

Table 5

\section{Standard Health Program}

\begin{tabular}{lll}
\hline & Women & Men \\
$n=64$ & $n=62$ \\
\hline Balanced diet & $50(78 \%)$ & $47(76 \%)$ \\
Diets & $15(23 \%)$ & $11(18 \%)$ \\
Fluid intake & $57(89 \%)$ & $54(87 \%)$ \\
Abstinence from alcohol & $24(38 \%)$ & $16(26 \%)$ \\
Abstinence from nicotine & $41(64 \%)$ & $45(73 \%)$ \\
Nutritional supplements & $21(33 \%)$ & $17(27 \%)$ \\
Preventive medical check-ups & $53(83 \%)$ & $41(66 \%)$ \\
Regular exercise & $53(83 \%)$ & $50(81 \%)$ \\
Sport & $35(55 \%)$ & $39(63 \%$ \\
Gym & $10(16 \%)$ & $8(13 \%)$ \\
Wellness & $20(31 \%)$ & $15(24 \%)$ \\
Others & $9(14 \%)$ & $6(10 \%)$ \\
\hline
\end{tabular}

Notes. Multiple answers were possible.

On average, the sum of the nomination frequencies for the standard health program is 5.85 points $(S D=$ 2.07).

The sum of the nominal frequencies of the standard health program correlates highly significant with the sum of the nominal frequencies of the standard beauty program $(r=0.343, p<0.001)$ as well as with the SES value $(r=0.271, p=0.003)$. 


\section{Anti-Aging}

To find out which parts of the body are considered most unpopular, illustrations of the male and female bodies, i.e., the front and back, were presented to the participants (see Figure 1). They received the following information: "Imagine you receive a voucher for surgical and non-surgical measures in a well-known beauty clinic. In the following figure, please mark the body parts that you would like to change" and "Please mark the body parts that you would like to change in your partner”. The results are shown in Tables 6 and 7.

Table 6

Body Parts to Change on the Own Body

\begin{tabular}{lll}
\hline & Women & Men \\
& $n=64$ & $n=62$ \\
\hline Hair & $10(16 \%)$ & $16(26 \%)$ \\
Forehead & $3(5 \%)$ & $1(2 \%)$ \\
Eyebrows & $6(9 \%)$ & $2(3 \%)$ \\
Eyes & $6(9 \%)$ & $1(2 \%)$ \\
Nose & $5(8 \%)$ & $7(11 \%)$ \\
Cheeks & $2(3 \%)$ & $1(2 \%)$ \\
Mouth & $6(9 \%)$ & - \\
Chin & $5(8 \%)$ & $2(3 \%)$ \\
Ears & $3(5 \%)$ & $2(3 \%)$ \\
Neck & $8(13 \%)$ & $3(5 \%)$ \\
Breast & $26(41 \%)$ & $2(3 \%)$ \\
Upper arms & $14(22 \%)$ & $3(5 \%)$ \\
Forearms & $3(5 \%)$ & - \\
Hands & $3(5 \%)$ & - \\
Belly & $34(53 \%)$ & $21(34 \%)$ \\
Hip & $11(17 \%)$ & $2(3 \%)$ \\
Private parts & - & - \\
Buttocks & $9(14 \%)$ & $2(3 \%)$ \\
Thighs & $20(31 \%)$ & - \\
Knees & $6(9 \%)$ & $2(3 \%)$ \\
Lower legs & $1(2 \%)$ & $1(2 \%)$ \\
Calves & $2(3 \%)$ & $1(2 \%)$ \\
\hline
\end{tabular}

Notes. Multiple answers were possible.

Women's most frequent answers were belly, breast, thighs, upper arms, and hip. The most frequent answers in men were belly, hair, nose, upper arms, and neck.

Table 7

Body Parts to Change on the Partner's Body

\begin{tabular}{lll}
\hline & Women & Men \\
& $n=64$ & $n=62$ \\
\hline Hair & $9(15 \%)$ & $5(8 \%)$ \\
Forehead & - & $1(2 \%)$ \\
Eyebrows & - & $3(5 \%)$ \\
Eyes & $1(2 \%)$ & $1(2 \%)$ \\
Nose & $3(5 \%)$ & $1(2 \%)$ \\
\hline
\end{tabular}


(table 7 continued)

\begin{tabular}{lll}
\hline & Women & Men \\
\hline Cheeks & $\mathrm{n}=64$ & $\mathrm{n}=62$ \\
Mouth & - & $1(2 \%)$ \\
Chin & $1(2 \%)$ & $1(2 \%)$ \\
Ears & - & - \\
Neck & $3(5 \%)$ & $1(2 \%)$ \\
Breast & - & $2(3 \%)$ \\
Upper arms & $1(2 \%)$ & $5(8 \%)$ \\
Forearms & $2(3 \%)$ & $3(5 \%)$ \\
Hands & - & - \\
Belly & - & $1(2 \%)$ \\
Hip & $23(39 \%)$ & $14(23 \%)$ \\
Private parts & $4(7 \%)$ & $1(2 \%)$ \\
Buttocks & $1(2 \%)$ & - \\
Thighs & $1(2 \%)$ & $3(5 \%)$ \\
Knees & $1(2 \%)$ & $5(8 \%)$ \\
Lower legs & $1(2 \%)$ & - \\
Calves & - & $1(2 \%)$ \\
\hline
\end{tabular}

Notes. Multiple answers were possible.

Women's requests for changes to their partner's body most often concerned the belly, hair, hips, nose, and ears. The most frequent change requests of men to the bodies of their partners were named with belly, thighs, hair, breast, and buttocks.

On average, the subjects wanted to change two body parts on their own body ( $S D=2.43$ ), with the difference ranging between 0 and 16 . Only 0.84 body parts on average should be changed on the partner's body $(S D=1.05$, Min. $=0, \operatorname{Max} .=4)$.

\section{Clothing Rules}

The majority of the participants affirmed the question whether there are rules for wearing certain clothes for women and men of advanced age. The concrete answers given were evaluated in content analysis using inductive category development (Mayring, 2008) (Table 8).

Table 8

Unwritten Rules for Wearing Clothes at an Advanced Age

\begin{tabular}{lllll}
\hline & Women about women & Women about men & Men about women & Men about men \\
\hline No rules & 13 & 15 & 14 & 19 \\
Form-fitting & 29 & 8 & 26 & 12 \\
Colourful & 2 & 7 & 3 & 2 \\
Depending on the weight & 5 & 3 & 2 & 3 \\
Depending on the age & 14 & 13 & 10 & 13 \\
Stylish, chic & 6 & 10 & 6 & 9 \\
Dresscode & 1 & 3 & 1 & 3 \\
Appropriate to type & 4 & 3 & 1 & 0 \\
\hline
\end{tabular}

Notes. Multiple answers were possible 
The following table shows examples for the categories that have been nominated (Table 9).

Table 9

Examples for the Nominated Categories

\begin{tabular}{|l|l|}
\hline Category & Examples \\
\hline No rules & $\begin{array}{l}\text { There are no rules. } \\
\text { Everybody can wear what they want. }\end{array}$ \\
\hline Form-fitting & $\begin{array}{l}\text { No super tight or short stuff. } \\
\text { Revealing clothes are inappropriate and undignified. }\end{array}$ \\
\hline Colourful & $\begin{array}{l}\text { White blouse, dark skirt. } \\
\text { Discreet colours, no patterns. }\end{array}$ \\
\hline Depending on the weight & $\begin{array}{l}\text { Avoid tight clothing for women from medium size upwards. } \\
\text { Hiding the fat rolls. }\end{array}$ \\
\hline Depending on the age & $\begin{array}{l}\text { No sexy clothes from 60 years, could be repulsive. } \\
\text { Do not publicly expose age-related physical weaknesses such as varicose veins. }\end{array}$ \\
\hline Stylish, chic & $\begin{array}{l}\text { Shirt or appropriate chic outfit, no sweatpants. } \\
\text { No socks in sandals, no shorts with brown nylon socks. }\end{array}$ \\
\hline Dress code & $\begin{array}{l}\text { Care in selection, especially in company. } \\
\text { Appropriate dress code in the working world and on official occasions. }\end{array}$ \\
\hline Appropriate to type & $\begin{array}{l}\text { The clothes should look good on the woman. } \\
\text { Basically everybody can wear what they want. } \\
\text { But of course it should match them. }\end{array}$ \\
\hline
\end{tabular}

\section{Discussion}

Getting old is exciting. It shows itself in many facets and our attitudes towards it are extremely ambivalent. As children, we wished to be old enough to be allowed to ride a bicycle on the road as soon as possible and only a few decades later we wished the youth back.

The marketing of youthfulness and beauty is having an effect. Our results show that women and men over 50 feel younger than they actually are. Rubin and Berntsen (2006) also discovered in their study that the perceived age of people over 40 years is on average $20 \%$ below their actual age. According to Westernhof and Barret (2005), feeling younger is equal to a positive age identity and positive self-esteem. This is presented as a successful way of dealing with age and aging. Critically, however, this result could also mean the opposite. The rejection of one's own age and aging is reflected in not accepting one's calendrical age and can also be read in colloquial statements, for example on birthday invitations: “60 is the new 40 !”. An effort not to use the term old for one's own person, as Jones (2006) cites, also points in this direction.

Feeling young and the desire to be young forever or to look young can be complemented by surveys of one's own body satisfaction. The women and men involved in the present study had a lower body satisfaction compared to the younger norm sample of Strauß and Richter-Appelt (1996). However, it should be noted that the two groups belong to different cohorts, which does not allow a direct comparison. As the current beauty boom is unlikely to have made up for the differences, however, the comparison is considered admissible in this case. The pressure of society with Western values and the ideal of an eternally youthful appearance could be one of the main reasons why people of advanced age show pronounced physical dissatisfaction.

Today's youth-oriented society is looking hard for methods that allow it to stay in good health for longer. Targeted dietary and surgical measures are used to counteract the external signs of aging, such as wrinkling, sagging of the tissue or hormonal weight gain. In this sample it was shown that a higher BMI and higher age are associated with less beauty behavior. 
The individual patterns of action for shaping one's own aging are diverse and underline the effectiveness of the ideals and strategies set by the media. For participants in this study, hairdressing and hair removal belong above all to the standard beauty program for both sexes.

Clarke and Griffin (2007) studied the perception of aging in relation to the use of beauty products, including anti-wrinkle creams, cosmetics, hair dyes, surgical and non-surgical cosmetic procedures. They examined a sample of 44 women from the age of 50 to 70 . The authors note that technologies and processes to maintain beauty are becoming more and more normal and idealized in today's society. The market for beauty products is growing and women are increasingly obliged to fight the physical consequences of aging. The women and men involved in our study would have their belly in particular undergo surgery. A possible explanation for this could be that the onset of menopause is accompanied by increased testosterone levels, which shifts the distribution of fat mainly to the women's waist and belly. Low testosterone levels are blamed for the big men's bellies. A change in the ratio of hip to waist (Voda, Christy, \& Morgen, 1991), which should be less than 80 inches for women and less than 102 inches for men, can be interpreted as farewell to the youthful body. The fact of lost fertility and the obvious signs of an aging body become a "narcissistic offence" (Mankowitz, 1994, p. 54) and lead to uncertainty in one's own identity.

Fashion and design help to stage one's own appearance. This study confirmed the assumptions regarding existing dress codes (Twigg, 2007). The majority of the participants were of the opinion that there are clothing rules. For women, wearing figure-hugging clothing is considered a no-go. Both sexes should ensure that the clothing is age-dependent and stylish. The importance of the functionality of clothing mentioned in the literature (Lurie, 1992) could not be found in the present study.

\section{Conclusions}

In summary, our results show that the topic of age and aging is predominantly negatively connoted. The loss of slenderness, beauty, and attractiveness is clearly in the spotlight. The numerous cosmetic, medical, and surgical possibilities should help to compensate for the aesthetic deficits. Looking into the mirror and the confrontation with the flaccid, thick body that goes with it, the beauty behavior becomes the last straw. In an effort to hide and conceal the signs of age and aging, personal identity is denied in favor of an externally legitimized identity (Schroeter, 2012).

The question remains unanswered as to at what age we are finally allowed to look old. Based on the available results it cannot be stated whether attractiveness and the desire to look younger lose importance in the fourth age or whether other topics are in the foreground. The hope remains that in the final phase of development we can accept changes in the body and individual inadequacies and associate our age and aging with an increase in maturity and experience. Since we are not known to age overnight, it is probably best to start today.

\section{References}

Baker, L., \& Gringart, E. (2009). Body image and self-esteem in older adulthood. Ageing \& Society, 29(6), 977-995.

Baltes, P. B. (1997). Die unvollendete Architektur der menschlichen Ontogenese: Implikationen für die Zukunft des vierten Lebensalters [The unfinished architecture of human ontogenesis: Implications for the future of the fourth age]. Psychologische Rundschau [Psychological Review], 48(4), 191-210. 
Baltes, P. B. (2007). Alter(n) als Balanceakt: Im Schnittpunkt von Fortschritt und Würde [Age and aging as a balancing act: At the intersection of progress and dignity]. In P. Gruss (Ed.), Die Zukunft des Alterns. Die Antwort der Wissenschaft. Ein Report der Max-Planck-Gesellschaft [The future of aging. The answer of science. A report by the Max Planck Society] (pp. 15-34). München: Beck.

Burke, N., Schaefer, L., \& Thompson, J. (2012). Body image. Encyclopedia of Human Behavior, 2, 365-371.

Cardona, B. (2008). "Healthy Ageing” policies and anti-aging ideologies and practices: On the exercise of responsibility. Medicine, Health Care and Philosophy, 11(4), 475-483.

Clarke, L., \& Griffin, M. (2007). The body natural and the body unnatural: Beauty work and aging. Journal of Aging Studies, 21(3), 187-201.

Cooley, E., Toray, T., Wang, M. C., \& Valdez, N. (2008). Maternal effects on daughters' eating pathology and body image. Eating Behaviors, 9, 52-61.

Derra, J. M. (2012). Das Streben nach Jugendlichkeit in einer alternden Gesellschaft. Eine Analyse altersbedingter Körperveränderungen in Medien und Gesellschaft [The pursuit of youthfulness in an aging society. An analysis of age-related body changes in media and society]. Baden-Baden: Nomos Verlagsgesellschaft.

Deutsche Gesellschaft für Ästhetisch-Plastische Chirurgie. (2017). Zahlen, Fakten und Trends in der Ästhetisch-Plastischen Chirurgie 2012/3 [Facts, figures and trends in aesthetic plastic surgery 2017]. Retrieved from https://www.dgaepc.de/wp-content/uploads/2017/11/DGAEPC-Statistik_2017.pdf

Featherstone, M., \& Hepworth, M. (1991). The mask of ageing and the postmodern life course. In M. Featherstone, M. Hepworth, and B. Turner (Eds.), The body: Social process and cultural theory (pp. 371-389). London: Sage.

Frederickson, B., \& Roberts, T.-A. (1997). Objectification theory: Toward understanding women’s lived experiences and mental health risks. Psychology of Women Quarterly, 21, 173-206.

Gildemeister, R., \& Robert, G. (2008). Geschlechtsdifferenzierungen in lebenszeitlicher Perspektive. Interaktion—Institution—Biografie [Gender differentiation from a lifelong perspective. Interaction—Institution—Biography]. Wiesbaden: VS Verlag für Sozialwissenschaften.

Gläßel, M.-L. (2011). Werbeschönheiten als Vorbild-Beeinflussen die Werbebilder die eigene Körperwahrnehmung von Frauen? [Advertising beauties as role models—Do advertising images influence women's own body perception?] In C. Holtz-Bacha (Ed.), Stereotype? Frauen und Männer in der Werbung [Stereotypes? Women and men in advertising] (pp. 260-297). Wiesbaden: VS Verlag für Sozialwissenschaften.

Höppner, G. (2011). Alt und schön. Geschlecht und Körperbilder im Kontext neoliberaler Gesellschaften [Old and beautiful. Gender and body images in the context of neoliberal societies]. Wiesbaden: VS Verlag für Sozialwissenschaften.

Hughes, V., Frontera, W., Roubenoff, R., Evans, W. J., \& Singh, M. A. (2002). Longitudinal changes in body composition in older men and women: Role of body weight change and physical activity. The American Journal of Clinical Nutrition, 76, 473-481.

Jones, R. L. (2006). “Older people” talking as if they are not older people: Positioning theory as an explanation. Journal of Aging Studies, 20(1), 79-91.

Klein, G. (2010). Soziologie des Körpers [Sociology of the body]. In G. Kneer and M. Schroer (Eds.), Handbuch Spezielle Soziologien [Handbook of special sociologies] (pp. 457-473). Wiesbaden: VS Verlag für Sozialwissenschaften.

Knoll, N., Rieckmann, N., Scholz, U., \& Schwarzer, R. (2004). Predictors of subjective age before and after cataract surgery: Conscientiousness makes a difference. Psychology and Aging, 19(4), 676-688.

Kruse, A., \& Wahl, H.-W. (2010). Zukunft Altern [Future of aging]. Heidelberg: Spektrum.

Lampert, T., Müters, S., Stolzenberg, H., \& Kroll, L. E. (2014). Messung des sozioökonomischen Status in der KiGGS-Studie [Measuring socio-economic status in the KiGGS study]. Bundesgesundheitsblatt [Federal Health Gazette], 57, 762-770.

Laslett, P. (1995). Das dritte Alter: Historische Soziologie des Alterns [The third age: Historical sociology of aging]. Weinheim, München: Juventa.

Lechleitner, M. (2013). Adipositas im Alter. Klinische Relevanz und Therapieoptionen [Obesity in old age. Clinical relevance and therapy options]. Zeitschrift für Gerontologie und Geriatrie [Journal of Gerontology and Geriatrics], 46, 398-402.

Levine, M., \& Chapman, K. (2011). Media influences on body image. In T. F. Cash and L. Smolak (Eds.), Body image: A handbook of science, practice, and prevention (pp. 101-109). New York: The Guilford Press.

Lurie, A. (1992). The language of clothes. London: Bloomsbury.

Maierhofer, R. (2007). Der gefährliche Aufbruch zum Selbst: Frauen, Altern und Identität in der amerikanischen Kultur. Eine anokritische Einführung [The dangerous start to the self: Women, aging, and identity in American culture. An anocritical introduction]. In U. Pasero, G. M. Backes, and K. R. Schroeter (Eds.), Altern in Gesellschaft [Aging in society]. Ageing_Diversity—Inclusion (pp. 111-127). Wiesbaden: VS Verlag für Sozialwissenschaften. 
Mankowitz, A. (1994). Auf neue Weise fruchtbar: Der seelische Prozess der Wechseljahre [Fertile in a new way: The mental process of menopause]. München: Kreuz.

Martin, M., \& Kliegel, M. (2008). Psychologische Grundlagen der Gerontologie [Psychological basics of gerontology] (2nd ed.). Stuttgart: Kohlhammer.

Mayring, P. (2008). Qualitative Inhaltsanalyse. Grundlagen und Techniken [Qualitative content analysis: Basics and techniques] (10th ed.). Weinheim, Basel: Beltz.

Muise, A., \& Desmarais, S. (2010). Women’s perceptions and use of “anti-aging” products. Sex Roles, 63(1), 126-137.

Öberg, P., \& Tornstam, L. (1999). Body images among men and women of different ages. Ageing and Society, 19, 629-644.

Petersen, A., \& Seear, K. (2009). In search of immortality: The political economy of anti-aging medicine. Medicine Studies, 1(3), 267-279.

Pook, M., Brähler, E., \& Tuschen-Caffier, B. (2009). Figurunzufriedenheit von Frauen in Abhängigkeit vom Lebensalter: Normative Daten für den Fragebogen zum Figurbewusstsein [Figure dissatisfaction of women depending on their age: Normative data for the questionnaire on figure awareness]. Verhaltenstherapie [Behavior Therapy], 19(1), 14-20.

Posch, W. (2009). Projekt Körper. Wie der Kult um die Schönheit unser Leben prägt [Project body. How the cult of beauty shapes our lives]. Frankfurt: Campus.

Rexbye, H., \& Povlsen, J. (2007). Visual signs of ageing: What are we looking at? International Journal of Ageing and Later Life, 2(1), 61-83.

Rubin, D. C., \& Berntsen, D. (2006). People over forty feel 20\% younger than their age: Subjective age across the lifespan. Psychonomic Bulletin \& Review, 13(5), 776-780.

Schroeter, K. (2012). Altersbilder als Körperbilder: Doing Age by Bodyfication [Age images as body images: Doing age by bodyfication]. In F. Berner, J. Rossow, and K.-P. Schitzer (Eds.), Individuelle und kulturelle Altersbilder. Expertisen zum 6. Altenbericht der Bundesregierung [Individual and cultural images of age. Expert reports on the Federal Government's 6th Report on the Gerontology of the Elderly] (pp. 154-229). Wiesbaden: VS Verlag für Sozialwissenschaften.

Slevin, K. F. (2010). If I had lots of money...I'd have a body makeover: Managing the aging body. Social Forces, 88(3), 1003-1020.

Smirnova, M. H. (2012). A will to youth: The woman's anti-aging elixir. Social Science \& Medicine, 75(7), 1236-1243.

Sontag, S. (1979). The double standard of aging. In V. Carver and P. Liddiard (Eds.), An aging population: A reader and sourcebook (pp. 72-80). New York: Holmes \& Meier.

Sorkin, J. D., Muller, D. C., \& Andres, R. (1999). Longitudinal change in height of men and women: Implications for interpretation of the Body Mass Index. American Journal of Epidemiology, 150(9), 969-977.

Statistik Austria. (2017). Equivalent household disposable income in Austria. Retrieved from https://www.statistik.at/web_de/statistiken/menschen_und_gesellschaft/soziales/haushalts-einkommen/index.html

Strauß, B., \& Richter-Appelt, H. (1996). Fragebogen zur Beurteilung des eigenen Körpers (FBeK) [Questionnaire for the assessment of the own body]. Göttingen: Hogrefe.

Thomae, H. (1993). Die Bonner Gerontologische Längsschnittstudie (BOLSA) [The Bonn longitudinal gerontological study]. Zeitschrift für Gerontologie [Journal of Gerontology], 26, 142-150.

Tiggemann, M., \& McCourt, A. (2013). Body appreciation in adult women: Relationships with age and body satisfaction. Body Image, 10(4), 624-627.

Twigg, J. (2007). Clothing, age and the body: A criticial review. Ageing \& Society, 27(2), 285-305.

Volkert, J., Klee, G., Kleimann, R., Scheurle, U., \& Schneider, F. (2003). Operationalisierung der Armuts-und Reichtumsmessung: Schlussbericht an das Bundesministerium für Gesundheit und Soziale Sicherung. [Operationalization of Poverty and Wealth Measurement: Final Report to the Federal Ministry of Health and Social Security.] Retrieved from http://www.iaw.edu/tl_files/dokumente/a322.pdf

Voda, A. M., Christy, N. S., \& Morgan, J. M. (1991). Body composition changes in menopausal women. Women \& Therapy, 11(2), 71-96.

Walter, U., Hager, K., \& Lux, R. (2008). Die alternde Bevölkerung: Demographie, gesundheitliche Einschränkungen, Krankheiten und Prävention unter Sex- und Gender-Fokus [The ageing population: Demography, health restrictions, diseases and prevention under sex and gender focus]. In A. Rieder and B. Lohff (Eds.), Gender Medizin. Geschlechtsspezifische Aspekte für die Klinische Praxis [Gender medicine. Gender-specific aspects for clinical practice] (pp. 467-505). Wien: Springer.

Weber, G., Ferring, D., \& Glück, J. (2008). Prognose von subjektivem Wohlbefinden im Alter: Ausgewählte Ergebnisse aus der European Study on Well-Being (ESAW-Projekt) [Prognosis of subjective well-being in old age: Selected results from the European Study on Well-Being]. In S. Zank and A. Hedtke-Becker (Eds.), Generationen in Familie und Gesellschaft im demographischen Wandel [Generations in family and society during demographic change] (pp. 55-70). Stuttgart: Kohlhammer. 
Weiss, D., \& Lang, F. R. (2012). “They are old but” I feel younger: Age-group dissociation as a self-protective strategy in old age. Psychology and Aging, 27(1), 153-163.

Westerhof, G. J., \& Barrett, A. E. (2005). Age identity and subjective well-being: A comparison of the United States and Germany. The Journals of Gerontology, 60(3), 129-136.

WHO. (2000). Obesity_Preventing and managing the global epidemic. Report of a WHO consultation on obesity (Technical Report Series 894). Geneva: Word Health Organization.

WHO. (2004). Preventing and managing the global epidemic of obesity. Report of the World Health Organization Consultation of Obesity. Geneva: World Health Organization.

Zamboni, M., Mazzali, G., Zoico, E., Harris, T. B., Meigs, J. B., Di Francesco, V., Fantin, F., \& Bissoli, L. (2005). Health consequences of obesity in the elderly: A review of four unresolved questions. International Journal of Obesity, 29, 1011-1029. 